\title{
MMP-3 Mediates Psychosine-Induced Globoid Cell Formation: Implications for Leukodystrophy Pathology
}

Kumiko Ijichi

University of Connecticut School of Medicine and Dentistry

Graham D. Brown

University of Connecticut School of Medicine and Dentistry

Craig S. Moore

University of Connecticut School of Medicine and Dentistry

Paige N. Winokur

University of Connecticut School of Medicine and Dentistry

Roberto Pagarigan

University of Connecticut School of Medicine and Dentistry

See next page for additional authors

Follow this and additional works at: https://opencommons.uconn.edu/uchcres_articles

Part of the Life Sciences Commons, and the Medicine and Health Sciences Commons

\section{Recommended Citation}

Ijichi, Kumiko; Brown, Graham D.; Moore, Craig S.; Winokur, Paige N.; Pagarigan, Roberto; and Crocker, Stephen J., "MMP-3 Mediates Psychosine-Induced Globoid Cell Formation: Implications for Leukodystrophy Pathology" (2013). UCHC Articles -

Research. 206.

https://opencommons.uconn.edu/uchcres_articles/206 
Authors

Kumiko Ijichi, Graham D. Brown, Craig S. Moore, Paige N. Winokur, Roberto Pagarigan, and Stephen J. Crocker 


\title{
MMP-3 Mediates Psychosine-Induced Globoid Cell Formation: Implications for Leukodystrophy Pathology
}

\author{
Kumiko ljichi ${ }^{1}$, Graham D. Brown ${ }^{1}$, Craig S. Moore ${ }^{1}$, Jean-Pyo Lee ${ }^{2}$, Paige N. Winokur ${ }^{1}$, \\ Roberto Pagarigan ${ }^{1}$, Evan Y. Snyder ${ }^{2}$, Ernesto R. Bongarzone ${ }^{3}$, and Stephen J. Crocker ${ }^{1}$ \\ ${ }^{1}$ Department of Neuroscience, University of Connecticut Health Center, Farmington, CT \\ ${ }^{2}$ Stem Cells and Regenerative Biology, Sanford-Burnham Medical Research Institute, La Jolla, \\ $\mathrm{CA}$
}

${ }^{3}$ Department of Anatomy and Cell Biology, College of Medicine, University of Illinois, Chicago, IL.

\begin{abstract}
Globoid cell leukodystrophy (GLD) or Krabbe disease, is a fatal demyelinating disease attributed to mutations in the galactocerebrosidase (GALC) gene. Loss of function mutations in GALC result in accumulation of the glycolipid intermediate, galactosylsphingosine (psychosine). Due to the cytotoxicity of psychosine, it has been hypothesized that accumulated psychosine underlie the pathophysiology of GLD. However, the cellular mechanisms of GLD pathophysiology remain unclear. Globoid cells, multinucleated microglia/macrophages in the central nervous system (CNS), are a defining characteristic of GLD. Here we report that exposure of primary glial cultures to psychosine induces the expression and the production of matrix metalloproteinase (MMP)-3 that mediated a morphological transformation of microglia into a multinucleated globoid cell type. Additionally, psychosine-induced globoid cell formation from microglia was prevented by either genetic ablation or chemical inhibition of MMP-3. These effects are microglia-specific as peripheral macrophages exposed to psychosine did not become activated or express increased levels of MMP-3. In the brain from twitcher mice, a murine model of human GLD, elevated MMP-3 expression relative to wild-type littermates was contemporaneous with disease onset and further increased with disease progression. Further, bone marrow transplantation (BMT), currently the only therapeutically beneficial treatment for GLD, did not mitigate the elevated expression of MMP-3 in twitcher mice. Hence, elevated expression of MMP-3 in GLD may promote microglial responses to psychosine that may represent an important pathophysiological process in this disease and its treatment.
\end{abstract}

\section{Keywords}

microglia; macrophage; astrocyte; multinucleated cell; psychosine; twitcher mice

(C) 2013 Wiley Periodicals, Inc.

Address correspondence to Stephen J. Crocker, Department of Neuroscience, University of Connecticut Health Center, 263

Farmington Avenue, MC-3401 Farmington, CT 06510, USA. crocker@uchc.edu.

Craig S. Moore is currently at Neurological Unit, Montreal Neurological Institute, McGill University, Montreal, Quebec, Canada. Jean-Pyo Lee is currently at Center for Stem Cell Research and Regenerative Medicine, Tulane University, New Orleans, LA, USA. Additional Supporting Information may be found in the online version of this article. 


\section{INTRODUCTION}

Leukodystrophies are rare genetic diseases affecting CNS white matter. Globoid cell leukodystrophy (GLD), also known as Krabbe disease (Krabbe, 1916), is a commonlypediatric de/dysmyelinating disease with an incidence of about 1 in 100,000 (Duffner et al., 2009). GLD has been attributed to a deficiency of the lysosomal enzyme, galactocerebrosidase (GALC), resulting from loss of function mutations in the $G A L C$ gene (Wenger, 2001). These loss of function mutations in GALC result in a metabolic defect and an accumulation of a sphingolipid intermediate, galactosylsphingosine (psychosine) (Suzuki and Suzuki, 1970). The excessive accumulation of psychosine in oligodendrocytes coupled with the toxicity of this metabolite has led to the "psychosine hypothesis" of GLD (Miyatake and Suzuki, 1972; Suzuki, 1998). This hypothesis proposes that elevated levels of psychosine cause the death of oligodendrocytes, which results in the prominent white matter pathology of GLD. However, when oligodendrocytes from the twitcher mouse model of this disease are transplanted into dysmyelinating shiverer mice, these oligodendrocytes differentiate and myelinate (Kondo et al., 2005). Thus, oligodendrocyte cell death and demyelination in GLD are not a cell-autonomous process.

Microgliosis and infiltration of peripheral macrophages into the CNS parenchyma are notable pathologic changes in GLD. Robust microglial activation in the brains of GLD patients provide a unique and defining feature of this disease: they transform into highly active, multinucleated phagocytes referred to as "globoid cells." These globoid cells are also observed in animal models of this disease (Suzuki, 1985). Globoid cells are known to develop from phagocytes during the course of this disease; however, it is not clear whether these giant multinucleated cells arise from resident CNS microglia and/or infiltrating macrophages. Discerning which cell types contribute to the formation and activation of these highly activated phagocytes is expected to provide new insights into the pathogenesis of GLD.

In a variety of demyelinating diseases, there is a well-established role for matrix metalloproteinases (MMPs), a family of extracellular endopeptidases that play significant roles in tissue remodeling and regeneration (Yong et al., 2001). MMPs are known to cleave all components of the extracellular matrix (ECM) and thereby serve important homeostatic functions. Particularly relevant to a potential role in GLD, dysregulated activities of MMPs have been associated with a wide variety of neurodegenerative and demyelinating diseases, including multiple sclerosis. A role for MMPs in a leukodystrophy has not been previously reported. In multiple sclerosis, elevated expression of MMPs by leukocytes facilitates the extravasation of autoreactive T cells into the CNS parenchyma (Gijbels et al., 1994). Increased expression of MMPs within the CNS is also thought to promote tissue degeneration (Pagenstecher et al., 1998). In an animal model of Parkinson's disease, for instance, MMP-3 in particular, has been shown to be a potent activator of microglia leading to neurodegeneration (Kim et al., 2005). Since microgliosis and invasion of peripheral macrophages into the CNS represents a primary pathology in GLD, we hypothesized a role for MMP-3 in GLD.

Herein, we report that psychosine-induced expression of MMP-3 is responsible for microglial activation and development of multi-nucleated globoid-like cells in primary murine glial cultures. Elevated expression of MMP-3 in the CNS of twitcher mice, which was not mitigated by bone marrow transplantation (BMT), the only therapeutically beneficial treatment for GLD, suggests a role for MMP-3 in the pathology of GLD. Together these data provide the first demonstration of MMP involvement in a leukodystrophy. 


\section{MATERIALS AND METHODS}

\section{Mice}

All protocols were performed in accordance with animal use and care protocol approved by Institutional Animal Care and Use Committees (IACUC). For cell culture experiments, all procedures using wild-type C57BL/6 and MMP-3 knockout (KO) neonates were performed at the University of Connecticut Health Center. Bone marrow transplant experiments were performed at the University of Illinois at Chicago.

\section{Preparation of Primary Mixed Glial Cultures}

Cultures were prepared from postnatal day (P) 0-3 wild-type C57BL/6 or MMP-3 KO mouse pups. Briefly, forebrains were stripped of meninges, chopped into fine pieces, and dissociated using a neural tissue dissociation kit (papain) according to the manufacturer's protocol (Miltenyi Biotec, Auburn, CA). The single cell suspension was then cultured in T75 tissue culture flasks (Grenier Bio-One, Germany) in DMEM (Gibco, Carlsbad, CA) supplemented with $10 \%$ fetal calf serum (FBS; Atlanta Biologicals, Lawrenceville, GA), penicillin (100 U/mL: Sigma Aldrich, St. Louis, MO) and streptomycin $(100 \mathrm{mg} / \mathrm{mL}$, Sigma Aldrich). After 12 to $16 \mathrm{hr}$, all nonadherent cells were removed and fresh media was added to the adherent cells. Mixed glial cultures were utilized experimentally when the confluent astrocytic monolayer was established.

\section{Purified Glial Cultures}

Primary mixed glial cultures were established, as described above. For purified microglial cultures, confluent mixed glial cultures were shaken using orbital shaker at $110 \mathrm{rpm}$ at $37^{\circ} \mathrm{C}$ 3 to $4 \mathrm{hr}$ to allow the loosely adhered microglia to detach from the astrocytic monolayer. Media was supplied with $25 \mathrm{mM}$ HEPES (Invitrogen, Grand Island, NY) and $25 \mathrm{mM}$ sodium bicarbonate (Invitrogen) to buffer $\mathrm{pH}$ changes in the absence of $\mathrm{CO}_{2}$. Following the shaking, media containing detached microglia was collected and manually counted using a hemacytometer. Cells were re-plated into six-well plates in mixed glial conditioned media, and used experimentally as a purified microglial culture after 2 to 3 days of incubation at $37^{\circ} \mathrm{C}$. Enriched astrocyte cultures were acquired by culturing the remaining adherent cells following 3 to $4 \mathrm{hr}$ shaking and collection of detached microglia, as described above. Fresh media was added to these cultures and incubated for 3 to 5 days at $37^{\circ} \mathrm{C}$ before any experimental manipulation.

\section{Psychosine Treatment and Characterization of Globoid Cells in Culture}

Mixed glial cell cultures were established from P0-P3 C57BL/6 or MMP-3 KO mice, as described above. When confluent, culture media was removed and cells were washed once in $1 \times$ PBS, then detached using a $0.25 \%$ Trypsin solution (Invitrogen). Cells were spun, washed with $1 \times$ PBS, then re-suspended in culture media, counted and plated at a density of $5.0 \times 10^{4} / \mathrm{mL}$ on circular glass cover-slips (Fisher Scientific, Pittsburgh, PA) coated in $5 \mu \mathrm{g} /$ $\mathrm{mL}$ laminin (Sigma Aldrich). Six replicates were performed per treatment. Cells were allowed to adhere for 4 to 5 days at $37^{\circ} \mathrm{C}$ with $5 \% \mathrm{CO}_{2}$, and treated with either culture media (untreated control); psychosine (10 $\mu \mathrm{M}$, Sigma Aldrich) (Im et al., 2001); psychosine + the broad-spectrum MMP inhibitor, GM6001 (12.5 $\mu \mathrm{M}$, Calbiochem, Billerica, MA); psychosine + GM6001i (inactive GM6001 analogue: $12.5 \mu \mathrm{M}$, Calbiochem); or vehicle control ( $0.13 \%$ of DMSO, Sigma Aldrich; and $0.02 \%$ ethanol, Sigma Aldrich). For study using MMP-3 specific inhibitor, NNGH (0.1 $\mu$ M, Enzo Life Sciences, Farmingdale, NY) was used in the same paradigm of GM6001. Treatments were supplemented every $48 \mathrm{hr}$, at the same concentrations, over 7 days of the experiment. We defined globoid cell by immunocyto-chemistry (see below) as Iba-1+ with a rounded amoeboid-like morphology 
and multinucleated. Representative images were taken using an Olympus IX71 fluorescent microscope and Eclipse imaging software (available at: empix.com). Numbers of globoid cells were quantified by counting the number of Iba-1+ cells in four separate areas per coverslip ( $n=3$ replicates totaling 12 images per treatment group were counted).

\section{Immunocytochemistry}

Cells were fixed on laminin-coated circular glass cover-slips in freshly prepared $4 \%$ paraformaldehyde (PFA, Sigma Aldrich) for $10 \mathrm{~min}$ at room temperature for $15 \mathrm{~min}$., then blocked and permeabilized with 0.2\% Triton X-100 (Sigma Aldrich) in PBS with 5\% normal goat serum (Invitrogen) for $1 \mathrm{hr}$. Fixed cells were incubated at $37^{\circ} \mathrm{C}$ using the microglial marker Iba-1 (1:500; Wako, Richmond, VA), glial fibrillary acidic protein (GFAP)-Cy3 (1:1,000; Sigma Aldrich) or GFAP (1:1,000; Dako, Carpinteria, CA), and MMP-3 (Calbiochem; 1:500) primary antibodies in 5\% normal goat serum for $1 \mathrm{hr}$. Following incubation, cells were washed three times in PBS for 10 min each. Cover-slips were then incubated at $37^{\circ} \mathrm{C}$ with 1:500 Alexa Fluor ${ }^{\circledR} 594$ and/or 488 (Invitrogen) and 1:1,000 DAPI (Invitrogen) for $45 \mathrm{~min}$ followed by three washes in $1 \times$ PBS for $10 \mathrm{~min}$ each. Finally, coverslips were mounted in Fluoromount-G ${ }^{\mathrm{TM}}$ (Southern-Biotech, Birmingham, $\mathrm{AL})$.

\section{Quantitative Real-Time Polymerase Chain Reaction (qRT-PCR)}

Total RNA was isolated from cultured cells, as described previously (Moore et al., 2011), and reverse transcribed into complementary DNA (cDNA) (iScript cDNA synthesis kit, BioRad, Hurcules, CA) according to the manufacturer's protocol. Synthesized cDNA samples were amplified using PCR primers specific to $m m p-3$ and $T N F$ mRNA (Integrated DNA Technologies, Coralville, IA), as employed previously (Chen et al., 2009); [MMP-3: forward 5'-GGA AAT CAG TTC TGG GCT ATA CGA-3', reverse, 5'-TAG AAA TGG CAG CAT CGA TCT TC-3'; TNF: forward 5'-GAC CCT CAC ACT CAG ATC ATC TTC T-3', reverse 5'-CCT CCA CTT GGT GGT TTG CT-3'] and SsoFast ${ }^{\mathrm{TM} E v a G r e e n}{ }^{\circledR}$ Supermix (Bio-Rad), according to the manufacturer's protocol. Amplification of target cDNA was analyzed by a Mastercycler ${ }^{\circledR}$ ep realplex (Eppendorf, Hauppauge, NY). Primers for GAPDH were used to assess general expression level of housekeeping gene among samples; GAPDH: forward 5'-ACC ACC ATG GAG AAG GC-3', reverse, 5'-GGC ATG GAC TGT GGT CAT GA-3'. For peripheral blood and macrophage sample, ribosomal unit $18 \mathrm{~S}$ was targeted as a housekeeping gene (18S: forward: $5^{\prime}$-AGT TGG TGG AGC GAT TTG-3', reverse: 5'-TTG CTC AAT CTC GGG TG-3'). Relative expression of mRNA was calculated using the comparative cycle threshold analysis $\left(\Delta C_{\mathrm{T}}\right)$, as previously described (Livak and Schmittgen, 2001).

\section{Microglial Phagocytosis Assay}

Primary mixed glial cultures were prepared, as described above, from P0 to P3 wild-type C57BL $/ 6$ mice. Cultures were plated at a density of $1 \times 10^{5}$ cells $/ \mathrm{mL}$ on laminin-coated glass coverslips and treated for 7 consecutive days with PBS, psychosine $(10 \mu \mathrm{M})$, or psychosine $(10 \mu \mathrm{M})$ and GM6001 $(12.5 \mu \mathrm{M})$. At $48 \mathrm{hr}$ before fixation, FITC-labeled latex beads (Cayman Chemical Company; Ann Arbor, MI) were added to all treatment groups. Cells were then incubated at $37^{\circ} \mathrm{C}$ for the duration of the experiment and then fixed using $4 \%$ PFA in PBS. Immunocytochemistry was then performed for Iba-1 and numbers of Iba-1+/FITC+ labeled cells were counted to determine the numbers of microglia that took up the beads for each treatment group ( $n=3$ /group; replicates of 9). 


\section{Peripheral Blood Cell Assay}

Peripheral blood was collected from wild-type mice by intracardial needle puncture and treated for $4 \mathrm{hr}\left(37^{\circ} \mathrm{C}, 5 \% \mathrm{CO}_{2}\right)$ with either psychosine $(10 \mu \mathrm{M})$ or lipopolysaccharide (LPS; $100 \mu \mathrm{g} / \mathrm{mL} ;$ Sigma Aldrich). To lyse the red blood cells, the treated samples were immediately incubated on ice with ammonium chloride (1:9, v:v) for $10 \mathrm{~min}$. Samples were spun at $1,000 \mathrm{~g}$ for $10 \mathrm{~min}$, followed by aspiration of ammonium chloride. The pellet was washed with $1 \mathrm{~mL}$ of RPMI (Gibco), spun at $1,000 \mathrm{~g}$ for $5 \mathrm{~min}$, and supernatant was aspirated. The pellet was re-suspended in TRIzol (invitrogen) and total RNA from peripheral blood white cells was isolated, as previously described (Moore et al., 2011).

\section{Peripheral Macrophage Collection}

Peripheral macrophages were collected from the peritoneal cavity of adult mice, as described previously (Ray and Dittel, 2010) with slight modifications. Briefly, adult wildtype C57BL/6 mice were anesthetized and 4 to $5 \mathrm{~mL}$ of ice cold PBS with 3\% FBS was injected intraperitoneally to each animal. Filled peritoneum was massaged well to detach the tissue-adhered macrophages into the cavity, followed by collection of injected PBS through $25 \mathrm{G}$ needle inserted into the peritoneal cavity. Collected cell suspension was centrifuged at 1,500 rpm for $7 \mathrm{~min}$, and collected cell pellet was resuspended in RPMI with 5\% FBS. Cells were plated in the plastic dish overnight $\left(37^{\circ} \mathrm{C}, 5 \% \mathrm{CO}_{2}\right)$ to allow macrophages to adhere at the bottom of dish. Media was then removed and adhered macrophages were plated at $5 \times$ $10^{6}$ cells $/ \mathrm{mL}$. The purity of differentially adhered macrophages was enumerated by flow cytometry (Supp. Info. Fig. 1). Plated macrophages were then treated with psychosine or LPS in the same regimen as described in peripheral blood cells assay (see above).

\section{Twitcher Mice}

Twitcher mice (GALC ${ }^{\text {twi }}$ Mice) are a well-characterized murine model of GLD, which is caused by a spontaneous mutation in the GALC gene. Mice were housed and bred at the Sanford-Burnham Institute (La Jolla, CA) where tissues were collected from homozygous GALC $^{\text {twi }} /$ GALC $^{\text {twi }}$ mice and wild-type littermates at different time points following birth P0, 10, 20, 31, and 40, as previously described (Taylor et al., 2006). Twitcher mice for BMT experiment were housed and bred at the University of Illinois at Chicago (Chicago, IL).

\section{Immunohistochemistry}

Twitcher mice and age-matched littermate control mice were transcardially perfused with PBS and 4\% PFA, and their brain was removed. Collected brains were immersed in 4\% PFA overnight and then in $30 \%$ sucrose solution. Brain tissue was paraffin-embedded and sectioned $15 \mu \mathrm{m}$ in thickness. Tissue sections mounted on slide glass were deparaffinized and dehydrated by series of xylene and ethanol, antigen-retrieved by heated citric acid buffer (0.01M, pH6.0), and blocked with 5\% normal goat serum in PBS for $1 \mathrm{hr}$.

Immunohistochemistry was then performed using primary antibodies against GFAP (1:1,000, Dako), Iba-1 (1:2,000, Wako), and MMP-3 (1:100, CalBioChem), diluted in PBS with $2 \%$ normal goat serum and incubated tissues in antibodies overnight at $4{ }^{\circ} \mathrm{C}$, followed by PBS wash. Immunoreactivity for each target was visualized by using fluorescent secondary antibodies, including Alexa Fluor ${ }^{\circledR} 594$ and 488 (1:500; Invitrogen), followed by PBS wash. The tissues were then coversliped using FluoroMount G (SouthernBiotech).

\section{Bone Marrow Transplantation in Twitcher Mice}

Bone marrow cells were obtained from C57BL/6J CD45.1 (8-12 weeks) as previously described (Galbiati et al., 2009). Briefly, tibiae and femora were flushed with $0.9 \%$ saline and the cells filtered (44- $\mu \mathrm{m}$ strainer; BD, San Diego, CA). The cellular eluant was then centrifuged at 1,500 rpm (5 min) and cell pellets incubated in lysis buffer to eliminate all red 
blood cells $\left(10 \mathrm{~min}\right.$ at $48^{\circ} \mathrm{C} ; 155 \mathrm{mM}$ ammonium chloride, $10 \mathrm{mM}$ potassium bicarbonate, $0.1 \mathrm{mM}$ EDTA, pH 8). Mononuclear cells were washed in saline and counted using a hemocytometer and then resuspended $\left(30 \times 10^{6}\right.$ cells $/ 20 \mu$ L saline) for intravenously infusion. Cells were injected in newborn Twitcher pups (1-2 days after birth) through the parietal vein, as previously described (Billingham and Brent, 1956; Sands and Barker, 1999). Transplanted mice were returned to their mothers without any other treatment.

\section{Statistical Analyses}

Data are presented as mean \pm SEM. A one-way ANOVA with Tukey's post hoc tests or unpaired Student's $t$-test was used to determine group differences. For all tests, $P<0.05$ was considered significant.

\section{RESULTS}

\section{Age-Dependent Increase in the CNS Expression of MMP-3 in Twitcher Mice}

Spontaneous mutations in GALC in C57/BL6 mice have been found to limit lifespan and produce neuropathology resembling human GLD. These "twitcher" mice are now established as an authentic model of GLD. To determine whether expression of MMP-3 was altered during the lifespan of twitcher mice, total RNA was isolated from whole brains of twitcher mice and wild-type littermates from time of birth (P0) through P40, at which $>95 \%$ mortality was observed among homozygous mutant mice. qRT-PCR evaluation of $\mathrm{mmp}-3$ mRNA revealed a significant increase in expression in twitcher mice compared with wildtype counterparts (Fig. 1A). This increase of MMP-3 expression coincided with the onset of clinical disease in twitcher mice, which is approximately P20 (Fig. 1A). Additionally, the increase of MMP-3 expression in twitcher mice showed a temporal correlation (Fig. 1A). The increase in MMP-3 expression in twitcher mouse brain relative to wild-type agematched controls was 7.5-fold by P40. To identify the cellular source of increased MMP-3 in the twitcher mouse brain, we performed immunohistochemistry for MMP-3 on brain tissue sections from P40 twitcher mice, a time point with the highest MMP-3 expression. Immunoreactivity of MMP-3 in twitcher mouse brain at P40 was frequently co-localized with GFAP+ astrocytes (Fig. 1B-D). Only a small portion of Iba-1+ microglia in twitcher mouse brain was co-localized with MMP-3 immunostaining (data not shown). Although neurons have also been implicated as a source of MMP-3 in other neurodegenerative disease models (Kim et al., 2005), our data support glia as a prominent source of MMP-3 production in GLD.

\section{Psychosine Regulates MMP-3 Expression from Glia, but Not Peripheral Immune Cells}

The increase of MMP- 3 in twitcher mice and its correlation with disease progression prompted us to examine if psychosine is a regulator of this response. To test this, mouse primary mixed glial cultures were treated with psychosine $(10 \mu \mathrm{M})$ at a dose previously reported to activate a macrophage cell line (Im et al., 2001). qRT-PCR analysis of RNA isolated from cultures treated with psychosine for 2,4 , or $20 \mathrm{hr}$ determined that there was a time-dependent increase of mmp-3 mRNA expression (Fig. 2, ANOVA, $* * P<0.01, * * * P<$ 0.001). In a second set of experiments, we tested whether the level of mmp-3 expression induced by psychosine was concentration-dependent. Psychosine concentration less than 10 $\mu \mathrm{M}$ did not influence glial cells with respect to MMP-3 transcription (data not shown). Additionally, analysis of increasing concentrations of psychosine (10-100 $\mu \mathrm{M})$ did not uncover a further enhancement of mmp-3 expression above that observed with $10 \mu \mathrm{M}$ (data not shown). At the highest concentration of psychosine tested $(100 \mu \mathrm{M})$ we observed significant cytotoxicity in the glial cultures (data not shown). Hence, we determined that psychosine transcriptionally induced $m m p-3$ expression in primary cultured glia. 
In a previous study, we determined that MMP- 3 is predominantly expressed by astrocytes in response to inflammatory stimuli (Crocker et al., 2006). To determine whether psychosineinduced mmp-3 expression in glial cultures was derived from astrocytes or microglia, or both, we next examined the cellular source of increased mmp-3 mRNA expression. Mixed glial cultures, enriched astrocyte cultures, or purified microglial cultures were treated with psychosine $(10 \mu \mathrm{M})$ for $20 \mathrm{hr}$, and the level of mmp-3 mRNA expression was analyzed using qRT-PCR. In our mixed glial cultures, which we have previously characterized, are comprised of approximately $95 \%$ astrocytes and $5 \%$ microglia at 25 days in vitro (Crocker et al., 2006; Milner and Campbell, 2002), can be grown and then mechanically sorted to enrich for astrocytes and separate purified microglial populations. Importantly, these culture conditions are not conducive to oligodendrocyte progenitor cell growth or maturation. Psychosine treatment of enriched astrocyte cultures significantly increased $m m p-3$ mRNA expression compared to untreated enriched astrocyte cultures $(P<0.01$, psycho-sine vS. untreated in mixed glia; $P<0.05$, psychosine $v s$. enriched astrocytes; Fig. 3A). However, application of psychosine to purified microglial cultures did not significantly increase mmp-3 expression when compared with either untreated purified microglia cultures or untreated mixed glial cultures ( $t$-test, $P=0.247 ;$ Fig. $3 C$ ). These results indicated that astrocytes were the primary source of $m m p-3$ expression in our cultures.

Because macrophages infiltrate the CNS during GLD, and macrophages have been implied in the formation of globoid cells in this disease, we next sought to determine whether peripheral immune cells, including macrophages specifically, could be induced to express MMP-3 in response to psychosine. Although psychosine treatment in primary purified microglial cultures moderately induced MMP-3 expression, treatment of peripheral blood or purified macrophages with equivalent concentrations of psychosine did not induce MMP-3 expression (Fig. 3B,D,F,H). qRT-PCR analysis of mmp-3 mRNA expression also revealed that LPS did not induce mmp-3 mRNA expression in peripheral blood samples (Fig. 3E). Since whole blood contains a myriad of cell types that may also regulate macrophage responsiveness, and peripheral blood samples contain only a small population of macrophages, we also isolated unstimulated peritoneal macrophages and challenged these purified cells with either psychosine or LPS. Flow cytometry determined that the proportion of macrophages in our preparations from peritoneal cavity were over 95\% (Supp. Info. Fig. 1). Treatment of purified peritoneal macrophages for $4 \mathrm{hr}$ with either psychosine or LPS revealed that neither psychosine nor LPS induced mmp-3 expression in peritoneal macrophages (Fig. 3G). However, analysis of tumore necrosis factor (TNF) expression in these same culture preparations determined that TNF expression was robustly induced by LPS (Fig. 3H; ANOVA, $P<0.05$ ), suggesting that the peritoneal macrophages were healthy and capable of responding to stimulation. These results indicate that microglia and peripheral macrophage populations markedly differ in their responses to psychosine and regulation of mmp-3 expression.

\section{Psychosine Induces “Globoid”-Like Cells in Primary Glial Cultures}

A hallmark pathology of GLD is the formation of globoid cells. Based on our finding that psychosine regulated MMP-3, an extracellular activator of microglia (Kim and Hwang, 2011), and previous work by Im et al. reported the development of multinucleated cells following psychosine treatment of BV2 and HEK293 cell lines (Im et al., 2001), we hypothesized that psychosine may induce a globoid-like phenotype in primary cultured glia. We next treated primary mixed glial cultures with $10 \mu \mathrm{M}$ psychosine for 7 consecutive days. Cultures were then analyzed by immunostaining for the microglial marker, Iba-1, the astrocyte marker, GFAP, and nuclear counterstain with DAPI. Control, untreated mixed glial cultures exhibited Iba-1+ cells with short-branched morphology that is typical of cultured microglia (Fig. 4A). In contrast, Iba-1+ glia exposed to psychosine exhibited an amoeboid- 
shaped phenotype, which was frequently multinucleated (Fig. 4C). These enlarged multinucleated cells resembled what would be referred to as "globoid" cells in the CNS pathology of GLD specimens. Indeed, the number of polynucleated Iba- $1+$ cells in psychosine-treated cultures was increased 5.5 fold compared to control conditions $(P<$ 0.001; Fig. 4C,D).

\section{Psychosine Does Not Induce Globoid-Like Cells in MMP-3KO Glia}

To determine whether MMP-3 specifically was the mediator of globoid cell formation in response to psychosine treatment, we prepared primary mixed glial cultures from MMP-3 knockout (KO) mice in addition to wild-type littermates, and applied psychosine (10 $\mu \mathrm{M})$ for 7 consecutive days, as outlined above. In MMP-3 KO cultures, psychosine did not induce mmp-3 expression, as we expected (data not shown). Moreover, globoid cells were not induced in MMP-3KO cultures by psychosine treatment (Fig. 5C,D), but were readily and robustly produced in wild-type cultures (Fig. 4). Microglial morphology in psychosinetreated MMP-3KO cultures was similar to untreated cultures (Fig. 5A,C). Thus, genetic ablation of MMP-3 prevented psychosine-induced globoid cell formation in vitro, suggesting that MMP-3 is required for psychosine-induced globoid cell formation.

\section{Globoid Cell Formation in Primary Glial Cultures Is Blocked by Chemical Inhibition of MMPs}

To determine whether increased expression of MMP-3 in response to psychosine exposure was directly related to the morphological transformation of microglia, we treated primary mixed glial cells with the broad-spectrum MMP inhibitor, GM6001, in conjunction with psychosine treatment for seven days. Microglial morphology was examined using immunostaining with Iba-1 as a microglial marker. Psychosine treatment in mixed glial culture induced the morphological change of Iba-1+ cells toward globoid-like cells (Fig. $6 \mathrm{~B}, \mathrm{~J})$. However, this morphological alteration in microglia was hampered when an MMP inhibitor was concomitantly added in the treatment (Fig. 6C,J). Next, we sought to determine whether morphological alterations in Iba-1+ microglia induced by psychosine were also associated with functional changes in phagocytosis. To test this, we cultured primary mixed glia, treated them with psychosine for seven days but applied fluorescent latex beads to the cultures for the last $48 \mathrm{hr}$ of the experiment. Immunostaining for Iba- $1+$ cells that also contained fluorescent beads was quantified as a functional index of phagocytosis in response to psychosine (Fig. 6D-F,K). Psychosine induced a fourfold increase in phagocytosis over basal levels observed in untreated, control cultures (ANOVA; $P<0.0001$ ). Treatment with the MMP inhibitor, GM6001, significantly reduced psychosineinduced phagocytosis (Fig. 6F,K). These data indicate that psychosine-induced activation of microglia in culture was mediated by MMPs.

\section{Globoid Cell Formation in Primary Glial Cultures is Blocked by a Peptide Inhibitor of MMP-3}

Because GM6001 is a nonselective, broad-spectrum MMP inhibitor, we wanted to ascertain whether selective inhibition of MMP-3 may also attenuate globoid cell formation in primary cultures treated with psychosine. To test this, we used the small peptide NNGH $\left(K_{\mathrm{i}}=130\right.$ nM for MMP-3), which exhibits greater specificity for MMP-3 than other MMPs. Coapplication of NNGH to psychosine-treated cultures resulted in a marked reduction in the number of globoid cells compared with cultures treated with psychosine alone (Fig. 6G-I,L). Thus, inhibition of MMPs including specific inhibition of MMP-3 attenuated the transformation of primary microglia into the highly activated globoid-like cell type. 


\section{Bone Marrow Transplantation Does Not Dampen Elevated MMP-3 Levels in Twitcher Mice}

Currently, the only treatment option for GLD cases is bone marrow transplantation (BMT) (Krivit et al., 1998). Recent clinical follow-up studies have determined that although BMT for GLD can alleviate symptoms, it does not prevent disease progression and eventually most patients succumb to ongoing progressive deterioration (Duffner et al., 2009). The clinical benefit of BMT is also observed in twitcher mice (Luzi et al., 2009; Yeager et al., 1984). Indeed, analysis of glial pathology in twitcher mice following BMT has reported reduced microgliosis and enhanced numbers of foamy macrophages that correlated with improved clinical outcome (Hoogerbrugge et al., 1988). We hypothesized that BMT may dampen the elevated mmp-3 expression within the CNS in GLD and this may be a contributing factor to the therapeutic benefit of BMT. To determine whether elevated mmp-3 expression in the twitcher CNS was affected by BMT, we next examined $m m p-3$ mRNA expression in twitcher mice that received BMT in the early postnatal period. A detailed characterization of these transplanted mice has been reported (Galbiati et al., 2009). Consistent with our previous analyses, symptomatic twitcher mice exhibited higher levels of $m m p-3$ mRNA than wild-type (control) mice (Fig. 7). However, expression of $m m p-3$ among twitcher mice that had received BMT, although exhibiting more inter-subject variability (range: 1.5 to 21-fold over wild-type) did not differ from non-BMT treated twitcher mice (Fig. 7). Hence, the sustained expression of mmp-3 in BMT-recipient twitcher mice may reflect a persistent disease process within the CNS that is not ameliorated by BMT.

\section{DISCUSSION}

In this study we have determined that psychosine regulates expression of MMP-3, which mediates the activation and proliferation of microglia toward a multinucleated globoid cell phenotype. Psychosine-induced increase in phagocytic activity and globoid cell formation were prevented by inhibition of MMP-3. Elevated MMP-3 expression was also identified in twitcher mice, an authentic animal model of GLD, and this elevation was not reversed by BMT. Hence, elevated MMP-3 expression in GLD may represent an important mediator of microglial activation in GLD.

The roles of microglia and macrophages in GLD are not currently well defined. Evidence for beneficial and detrimental functions for both of these phagocytic populations in GLD and twitcher mice have been provided in several previous studies by others (Kagitani-Shimono et al., 2005; Kondo et al., 2011; Matsushima et al., 1994). We hypothesize that sustained induction of MMP-3 by accumulated psychosine in the CNS of individuals with GLD promotes microglial activation and globoid cell formation, but not macrophage activation, which may promote myelin degeneration through the robust phagocytic activity of these microglia-derived cells. Our in vitro experiments would indicate that macrophages and microglia are functionally distinct cell types that respond in distinctly different ways to psychosine exposure. These results support an ontogenic separation of these related yet specialized phagocytic cell types (Ginhoux et al., 2010) and our findings provide a potentially unique distinction between microglia and macrophages in this disease through their differential propensity to be activated by psychosine.

While we hypothesize that the highly activated nature of globoid cells in vitro may reflect a pathogenic form of microglia that contribute to neuropathology in GLD, it is also plausible that highly activated phagocytes could represent an endogenous protective response to clear dead or dying cells to foster remyelination (Neumann et al., 2009). For instance, remyelination in a chemical lesion model of focal demyelination is impaired when microglia/macrophages are inhibited (Kotter et al., 2005; Li et al., 2005). When interpreted in the context of our results, the highly activated microglia in response to psychosine could 
represent a mode of myelin debris clearance that would allow for removal of growth inhibiting molecules and promote oligodendrocyte progenitor cell proliferation and differentiation (Neumann et al., 2009). Although these previous studies were not examined in the context of the twitcher mouse brain, recent work by Kondo et al. describe a possible protective function of microglia/macrophages in GLD (Kondo et al., 2011). Thus, it is plausible that psychosine-induced MMP-3-mediated microglial activation could be a robust but ultimately insufficient attempt to foster brain repair in the GLD CNS.

Our results may also indicate that globoid cells in GLD may be exclusively derived from resident microglia and provides an explanation for why globoid cells are not observed in association with demyelinating peripheral neuropathy in GLD (Siddiqi et al., 2006; Tanaka et al., 1988). Globoid cell formation in the CNS of human and animal GLD is traditionally believed as a secondary consequence followed by a primary oligodendrocyte death due to the accumulation of psychosine in oligodendrocytes (Takahashi and Suzuki, 1984). Our data demonstrate that microglia transformed toward a globoid cell-like morphology in response to psychosine treatment in vitro, however, our glial culture systems used in this study did not contain oligodendrocytes. Moreover, microglial activation and globoid cell formation are effects of psychosine on microglia that can occur independently of oligodendrocytes in culture. Thus, based on these data, microglial activation and globoid cell formation in GLD, rather than being a secondary response to CNS demyelination, may instead be a primary response to psychosine. In fact, it was previously reported that globoid cells were observed prior to the onset of disease and/or demyelination (Martin et al., 1981).

Overall, this work indicates that psychosine initiates changes in many cell types; including, microglia, astrocytes, and oligodendrocytes. In this context, our globoid cell assay using primary glial culture may be a practical model to test and understanding the pathological process of microglial activation by psychosine. For instance, identifying the proteolytic target(s) of MMP-3 on microglia may provide a novel strategy to better understand the specific actions of activated microglia and/or formation of globoid cells in GLD. While the pathogenic contribution of microglia can only be inferred from previous work, the contribution of MMP-3 toward GLD pathology was not directly addressed in this study. Future studies will be required to examine the specific contribution of MMP-3 in GLD neuropathology and elucidate whether this process impacts microglial activation, inflammatory profiles and globoid cell formation in vivo.

The proteolytic actions of MMPs are regulated by the tissue inhibitors of metalloproteinases (TIMPs) (Crocker et al., 2004). In a course of disease in twitcher mice, we examined the expression of TIMP-1, a timp gene that is robustly expressed during CNS demyelination that is also well-characterized endogenous inhibitor of MMP-3 (Gomis-Ruth et al., 1997). Our qRT-PCR analysis determined that expression of TIMP-1 increased only modestly over the same time frame relative to the robust increase in MMP-3 expression (data not shown). Moreover, expression of MMP-2 and -9 in the CNS of twitcher mice did not differ from the levels of expression in wild-type littermates throughout their postnatal development (data not shown). Hence, in the CNS of twitcher mice there is a dysregulation of certain MMPs, namely MMP-3, during the course of disease. Elevated expression of MMP-3 has been reported in a variety of CNS white matter disorders including multiple sclerosis and experimental models of spontaneous demyelination (D'Souza et al., 2002; Pagenstecher et al., 1998; Toft-Hansen et al., 2004; Ulrich et al., 2006). On the basis of previous studies, pathological actions of elevated MMP-3 expression in GLD could contribute to GLD pathology in two ways. First, we have shown that MMP-3 is important for the phenotypic activation of microglia (Kim et al., 2005), as we have also demonstrated in response to psychosine. Secondly, previous studies have shown that many myelin proteins are proteolytic targets of MMPs (Chandler et al., 1996; Milward et al., 2008), including MMP-3 
(Shiryaev et al., 2009). Hence, elevated MMP-3 production in the CNS of twitcher mice may contribute to destabilization of CNS myelin and oligodendrocyte death as well.

Currently, the primary therapy for GLD patients is BMT. The effectiveness of this stem cellbased therapy in GLD has been reported to be highly variable among human cases with limited long-term benefit for some patients (Duffner et al., 2009; Hoogerbrugge et al., 1988; Suzuki et al., 1988). Among twitcher mice, BMT increases lifespan and improves neuropathology but these mice still die prematurely (Hoogerbrugge et al., 1988; Yagi et al., 2005; Yeager et al., 1984). Previous discussions on the limited efficacy of the stem cell transplantation in GLD have indicated that microglial activity in twitcher mice remains high, even after neural stem cell transplantation (Pellegatta et al., 2006). Our data in this study may shed light on this pathology, namely that elevated MMP-3 expression in the CNS of twitcher mice was unaltered by BMT, although there is a possibility of delayed induction in MMP-3 expression by BMT. Thus, sustained induction of MMP-3 may represent an inherent limitation of BMT treatment for GLD. Abrogation of microglial activation, perhaps through MMP-3-targeted strategies may be a mode for controlling microglial activation that could enhance the therapeutic efficacy of BMT in GLD. Hence, persistent expression of MMP-3 in the GLD brain may represent a limitation of long-term prognosis for this treatment approach. In future, experiments designed to address the issue of the limited therapeutic window for BMT (Krivit et al., 1998) could potentially include adjunct MMP inhibiting therapy to address the excessive production of MMP-3 in the CNS compartment in this disease. Nevertheless, whether as a potential therapeutic target for GLD treatment, or as a source of basic understanding on MMP-3 regulation of microgliosis in GLD, additional study is expected to provide new information on the innate inflammatory response in GLD, how it may be regulated by MMP-3, as shown in this study, and potentially provide additional insights into MMP-3 in other diseases as well.

Formation of multinucleated giant cells are pathological hallmarks of many neurological diseases including amyotropic lateral sclerosis (ALS) (Fendrick et al., 2007), HIV encephalitis (Budka, 1986), Alzheimer's disease, acute disseminated encephalomyelitis, giant cell angiitis [associated with vasculitis in the CNS (Ciappetta et al., 2010)], gliomas and neuroepithelial tumors (Adamek et al., 2008) and other leukodystrophies as well (Budka, 1986; Elleder, 1984). Among these other diseases in which giant multinucleated microglia are found, elevated expression of MMP-3 has been reported in Alzheimer's disease (Yoshiyama et al., 2000). Although a pathological association between MMP-3 and formation of giant cells in these diseases has not been previously reported, our study would support this line of future investigation. Moreover, the mechanism by which multinucleated microglial cells are formed in response to psychosine, and mediated by MMP-3, may have an application toward the pathogenesis of these other neurodegenerative diseases. Future studies will explore the actions of MMP-3 on microglial cytokinesis, for instance (Kanazawa et al., 2000), in response to psychosine and other pathological stimuli that results in formation of multinucleated giant cells. The importance in pathogenic contribution of these multinucleated phagocytes toward neuropathology and disease progression will be required to fully understand the mechanism of these disease-associated changes in microglial phenotypes.

\section{Supplementary Material}

Refer to Web version on PubMed Central for supplementary material. 


\section{Acknowledgments}

The authors thank Dr. Gary A. Rosenberg (University of New Mexico) for providing us with MMP-3KO mouse founders, Matthew Hammond for assistance with flow cytometry, and Sarah MacIsaac for technical assistance.

Grant sponsor: Career Transition Award from the National Multiple Sclerosis Society (to S.J.C.); Grant number: T/ A 3021 A1/1T; Grant sponsor: National Institute of Health (to E.R.B.); Grant number: NIH RNS065808

\section{References}

Adamek D, Dec M, Sobol G, Urbanowicz B, Jaworski M. Giant cell ependymoma: a case report. Clin Neurol Neurosurg. 2008; 110:176-181. [PubMed: 18006220]

Billingham RE, Brent L. Further attempts to transfer transplantation immunity by means of serum. Br J Exp Pathol. 1956; 37:566-569. [PubMed: 13396140]

Budka H. Multinucleated giant cells in brain: A hallmark of the acquired immune deficiency syndrome (AIDS). Acta Neuropathol. 1986; 69:253-258. [PubMed: 3962603]

Chandler S, Cossins J, Lury J, Wells G. Macrophage metalloelastase degrades matrix and myelin proteins and processes a tumour necrosis factor-alpha fusion protein. Biochem Biophys Res Commun. 1996; 228:421-429. [PubMed: 8920930]

Chen YW, Boyartchuk V, Lewis BC. Differential roles of insulin-like growth factor receptor- and insulin receptor-mediated signaling in the phenotypes of hepatocellular carcinoma cells. Neoplasia. 2009; 11:835-845. [PubMed: 19724677]

Ciappetta P, D’Urso PI, Colamaria A, Lauta E, Cimmino A, D’Urso OF, Rossi R, Resta L, Ingravallo G. Giant cell angiitis of the central nervous system with atypical presentation. Neuropathology. 2010; 30:434-438. [PubMed: 19925563]

Crocker SJ, Milner R, Pham-Mitchell N, Campbell IL. Cell and agonist-specific regulation of genes for matrix metalloproteinases and their tissue inhibitors by primary glial cells. J Neurochem. 2006; 98:812-823. [PubMed: 16893421]

Crocker SJ, Pagenstecher A, Campbell IL. The TIMPs tango with MMPs and more in the central nervous system. J Neurosci Res. 2004; 75:1-11. [PubMed: 14689443]

D'Souza CA, Mak B, Moscarello MA. The up-regulation of stromelysin-1 (MMP-3) in a spontaneously demyelinating transgenic mouse precedes onset of disease. J Biol Chem. 2002; 277:13589-13596. [PubMed: 11830584]

Duffner PK, Caviness VS Jr, Erbe RW, Patterson MC, Schultz KR, Wenger DA, Whitley C. The longterm outcomes of presymptomatic infants transplanted for Krabbe disease: report of the workshop held on July 11 and 12, 2008, Holiday Valley, New York. Genet Med. 2009; 11:450-454. [PubMed: 19346954]

Elleder M. Histochemical observations of induction and depression of enzyme activities in various pathological conditions: Personal experience. Histochem J. 1984; 16:345-347. [PubMed: 6715188]

Fendrick SE, Xue QS, Streit WJ. Formation of multinucleated giant cells and microglial degeneration in rats expressing a mutant $\mathrm{Cu} / \mathrm{Zn}$ superoxide dismutase gene. J Neuroinflamm. 2007; 4:9.

Galbiati F, Givogri MI, Cantuti L, Rosas AL, Cao H, van Breemen R, Bongarzone ER. Combined hematopoietic and lentiviral gene-transfer therapies in newborn Twitcher mice reveal contemporaneous neurodegeneration and demyelination in Krabbe disease. J Neurosci Res. 2009; 87:1748-1759. [PubMed: 19185028]

Gijbels K, Galardy RE, Steinman L. Reversal of experimental autoimmune encephalomyelitis with a hydroxamate inhibitor of matrix metalloproteases. J Clin Invest. 1994; 94:2177-2182. [PubMed: 7989572]

Ginhoux F, Greter M, Leboeuf M, Nandi S, See P, Gokhan S, Mehler MF, Conway SJ, Ng LG, Stanley ER, Samokhvalov IM, Merad M. Fate mapping analysis reveals that adult microglia derive from primitive macrophages. Science. 2010; 330:841-845. [PubMed: 20966214]

Gomis-Ruth FX, Maskos K, Betz M, Bergner A, Huber R, Suzuki K, Yoshida N, Nagase H, Brew K, Bourenkov GP, Bartunik H, Bode W. Mechanism of inhibition of the human matrix metalloproteinase stromelysin-1 by TIMP-1. Nature. 1997; 389:77-81. [PubMed: 9288970] 
Hoogerbrugge PM, Suzuki K, Poorthuis BJ, Kobayashi T, Wagemaker G, van Bekkum DW. Donorderived cells in the central nervous system of twitcher mice after bone marrow transplantation. Science. 1988; 239:1035-1038. [PubMed: 3278379]

Im DS, Heise CE, Nguyen T, O’Dowd BF, Lynch KR. Identification of a molecular target of psychosine and its role in globoid cell formation. J Cell Biol. 2001; 153:429-434. [PubMed: 11309421]

Kagitani-Shimono K, Mohri I, Fujitani Y, Suzuki K, Ozono K, Urade Y, Taniike M. Antiinflammatory therapy by ibudilast, a phosphodiesterase inhibitor, in demyelination of twitcher, a genetic demyelination model. J Neuroinflamm. 2005; 2:10.

Kanazawa T, Nakamura S, Momoi M, Yamaji T, Takematsu H, Yano H, Sabe H, Yamamoto A, Kawasaki T, Kozutsumi Y. Inhibition of cytokinesis by a lipid metabolite, psychosine. J Cell Biol. 2000; 149:943-950. [PubMed: 10811833]

Kim EM, Hwang O. Role of matrix metalloproteinase-3 in neurodegeneration. J Neurochem. 2011; 116:22-32. [PubMed: 21044079]

Kim YS, Kim SS, Cho JJ, Choi DH, Hwang O, Shin DH, Chun HS, Beal MF, Joh TH. Matrix metalloproteinase-3: A novel signaling proteinase from apoptotic neuronal cells that activates microglia. J Neurosci. 2005; 25:3701-3711. [PubMed: 15814801]

Kondo Y, Adams JM, Vanier MT, Duncan ID. Macrophages counteract demyelination in a mouse model of globoid cell leukodystrophy. J Neurosci. 2011; 31:3610-3624. [PubMed: 21389217]

Kondo Y, Wenger DA, Gallo V, Duncan ID. Galactocerebrosidase-deficient oligodendrocytes maintain stable central myelin by exogenous replacement of the missing enzyme in mice. Proc Natl Acad Sci USA. 2005; 102:18670-18675. [PubMed: 16352725]

Kotter MR, Zhao C, van Rooijen N, Franklin RJ. Macrophage-depletion induced impairment of experimental CNS remyelination is associated with a reduced oligodendrocyte progenitor cell response and altered growth factor expression. Neurobiol Dis. 2005; 18:166-175. [PubMed: 15649707]

Krabbe K. A new familial, infantile form of brain sclerosis. Brain. 1916; 39:74-114.

Krivit W, Shapiro EG, Peters C, Wagner JE, Cornu G, Kurtzberg J, Wenger DA, Kolodny EH, Vanier MT, Loes DJ, Dusenbery K, Lockman LA. Hematopoietic stem-cell transplantation in globoid-cell leukodystrophy. N Engl J Med. 1998; 338:1119-1126. [PubMed: 9545360]

Li WW, Setzu A, Zhao C, Franklin RJ. Minocycline-mediated inhibition of microglia activation impairs oligodendrocyte progenitor cell responses and remyelination in a non-immune model of demyelination. J Neuroimmunol. 2005; 158:58-66. [PubMed: 15589038]

Livak KJ, Schmittgen TD. Analysis of relative gene expression data using real-time quantitative PCR and the 2(-Delta Delta C(T)) Method. Methods. 2001; 25:402-408. [PubMed: 11846609]

Luzi P, Abraham RM, Rafi MA, Curtis M, Hooper DC, Wenger DA. Effects of treatments on inflammatory and apoptotic markers in the CNS of mice with globoid cell leukodystrophy. Brain Res. 2009; 1300:146-158. [PubMed: 19748497]

Martin JJ, Leroy JG, Ceuterick C, Libert J, Dodinval P, Martin L. Fetal Krabbe leukodystrophy. A morphologic study of two cases. Acta Neuropathol. 1981; 53:87-91.

Matsushima GK, Taniike M, Glimcher LH, Grusby MJ, Frelinger JA, Suzuki K, Ting JP. Absence of MHC class II molecules reduces CNS demyelination, microglial/macrophage infiltration, and twitching in murine globoid cell leukodystrophy. Cell. 1994; 78:645-656. [PubMed: 8069913]

Milner R, Campbell IL. Cytokines regulate microglial adhesion to laminin and astrocyte extracellular matrix via protein kinase C-dependent activation of the alpha6beta1 integrin. J Neurosci. 2002; 22:1562-1572. [PubMed: 11880486]

Milward E, Kim KJ, Szklarczyk A, Nguyen T, Melli G, Nayak M, Deshpande D, Fitzsimmons C, Hoke A, Kerr D, Griffin JW, Calabresi PA, Conant K. Cleavage of myelin associated glycoprotein by matrix metalloproteinases. J Neuroimmunol. 2008; 193:140-148. [PubMed: 18063113]

Miyatake T, Suzuki K. Globoid cell leukodystrophy: Additional deficiency of psychosine galactosidase. Biochem Biophys Res Commun. 1972; 48:539-543. [PubMed: 5047687]

Moore CS, Milner R, Nishiyama A, Frausto RF, Serwanski DR, Pagarigan RR, Whitton JL, Miller $\mathrm{RH}$, Crocker SJ. Astrocytic tissue inhibitor of metalloproteinase-1 (TIMP-1) promotes 
oligodendrocyte differentiation and enhances CNS myelination. J Neurosci. 2011; 31:6247-6254. [PubMed: 21508247]

Neumann H, Kotter MR, Franklin RJ. Debris clearance by microglia: an essential link between degeneration and regeneration. Brain. 2009; 132:288-295. [PubMed: 18567623]

Pagenstecher A, Stalder AK, Kincaid CL, Shapiro SD, Campbell IL. Differential expression of matrix metalloproteinase and tissue inhibitor of matrix metalloproteinase genes in the mouse central nervous system in normal and inflammatory states. Am J Pathol. 1998; 152:729-741. [PubMed: 9502415]

Pellegatta S, Tunici P, Poliani PL, Dolcetta D, Cajola L, Colombelli C, Ciusani E, Di Donato S, Finocchiaro G. The therapeutic potential of neural stem/progenitor cells in murine globoid cell leukodystrophy is conditioned by macrophage/microglia activation. Neurobiol Dis. 2006; 21:314323. [PubMed: 16199167]

Ray A, Dittel BN. Isolation of mouse peritoneal cavity cells. J Vis Exp. 2010; 35:e1488.

Sands MS, Barker JE. Percutaneous intravenous injection in neonatal mice. Lab Anim Sci. 1999; 49:328-330. [PubMed: 10403452]

Shiryaev SA, Savinov AY, Cieplak P, Ratnikov BI, Motamedchaboki K, Smith JW, Strongin AY. Matrix metalloproteinase proteolysis of the myelin basic protein isoforms is a source of immunogenic peptides in autoimmune multiple sclerosis. PLoS One. 2009; 4:e4952. [PubMed: 19300513]

Siddiqi ZA, Sanders DB, Massey JM. Peripheral neuropathy in Krabbe disease: Effect of hematopoietic stem cell transplantation. Neurology. 2006; 67:268-272. [PubMed: 16864820]

Suzuki K. Genetic galactosylceramidase deficiency (globoid cell leukodystrophy, Krabbe disease) in different mammalian species. Neurochem Pathol. 1985; 3:53-68. [PubMed: 3895053]

Suzuki K. Twenty five years of the "psychosine hypothesis": A personal perspective of its history and present status. Neurochem Res. 1998; 23:251-259. [PubMed: 9482237]

Suzuki K, Hoogerbrugge PM, Poorthuis BJ, Bekkum DW. The twitcher mouse. Central nervous system pathology after bone marrow transplantation. Lab Invest. 1988; 58:302-309.

Suzuki K, Suzuki Y. Globoid cell leucodystrophy (Krabbe's disease): Deficiency of galactocerebroside beta-galactosidase. Proc Natl Acad Sci USA. 1970; 66:302-309. [PubMed: 5271165]

Takahashi H, Suzuki K. Demyelination in the spinal cord of murine globoid cell leukodystrophy (the twitcher mouse). Acta Neuropathol. 1984; 62:298-308. [PubMed: 6730907]

Tanaka K, Nagara H, Kobayashi T, Goto I. The twitcher mouse: accumulation of galactosylsphingosine and pathology of the sciatic nerve. Brain Res. 1988; 454:340-346. [PubMed: 3409017]

Taylor RM, Lee JP, Palacino JJ, Bower KA, Li J, Vanier MT, Wenger DA, Sidman RL, Snyder EY. Intrinsic resistance of neural stem cells to toxic metabolites may make them well suited for cell non-autonomous disorders: Evidence from a mouse model of Krabbe leukodystrophy. $\mathbf{J}$ Neurochem. 2006; 97:1585-1599. [PubMed: 16805770]

Toft-Hansen H, Nuttall RK, Edwards DR, Owens T. Key metalloproteinases are expressed by specific cell types in experimental autoimmune encephalomyelitis. J Immunol. 2004; 173:5209-5218. [PubMed: 15470066]

Ulrich R, Baumgartner W, Gerhauser I, Seeliger F, Haist V, Deschl U, Alldinger S. MMP-12, MMP-3, and TIMP-1 are markedly upregulated in chronic demyelinating theiler murine encephalomyelitis. J Neuropathol Exp Neurol. 2006; 65:783-793. [PubMed: 16896312]

Wenger, DA. Galactosylceramide lipidosis: Globoid cell leukodystrophy (Krabbe disease). McGrawHill; New York: 2001.

Yagi T, Matsuda J, Tominaga K, Suzuki K. Hematopoietic cell transplantation ameliorates clinical phenotype and progression of the CNS pathology in the mouse model of late onset Krabbe disease. J Neuropathol Exp Neurol. 2005; 64:565-575. [PubMed: 16042308]

Yeager AM, Brennan S, Tiffany C, Moser HW, Santos GW. Prolonged survival and remyelination after hematopoietic cell transplantation in the twitcher mouse. Science. 1984; 225:1052-1054. [PubMed: 6382609] 
Yong VW, Power C, Forsyth P, Edwards DR. Metalloproteinases in biology and pathology of the nervous system. Nat Rev Neurosci. 2001; 2:502-511. [PubMed: 11433375]

Yoshiyama Y, Asahina M, Hattori T. Selective distribution of matrix metalloproteinase-3 (MMP-3) in Alzheimer's disease brain. Acta Neuropathol. 2000; 99:91-95. [PubMed: 10672313] 

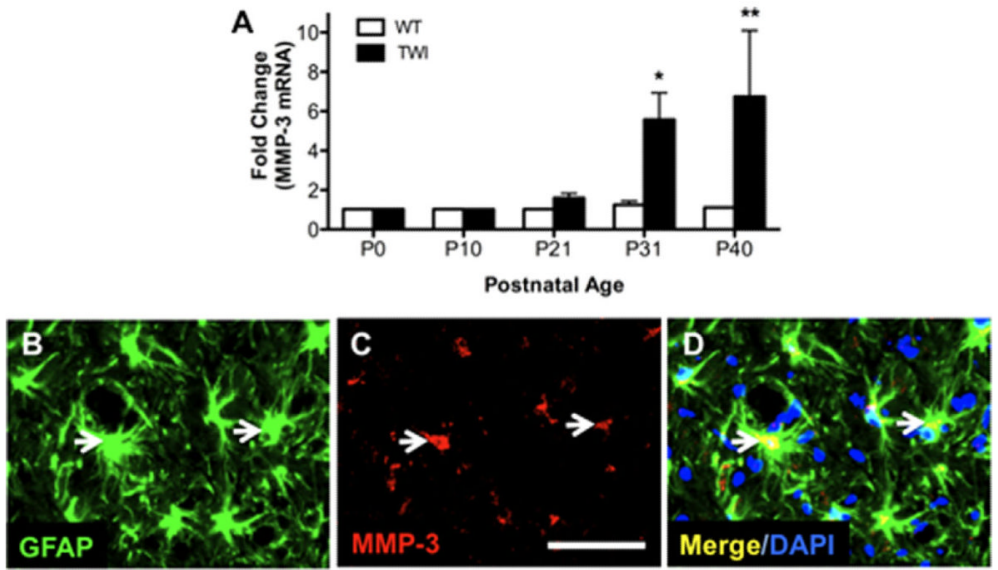

FIGURE 1.

Elevated astrocytic MMP-3 expression in twitcher mouse brain. (A) MMP-3 expression level in the brain of wild-type (WT) and twitcher (TWI) mice at various ages was quantified by qRT-PCR. (B-D) MMP-3 protein expression (red) was visualized by

immunohistochemistry from the brain section of P30 twitcher mouse. Note that MMP-3 immunoreactivity is co-localized (white arrows) with the astrocyte-specific marker, glial fibrillary acidic protein (GFAP; green). Data represent mean \pm SEM. $N=3$ /age/genotype, scale bar $=50 \mu \mathrm{m}$. [Color figure can be viewed in the online issue, which is available at wileyonlinelibrary.com.] 


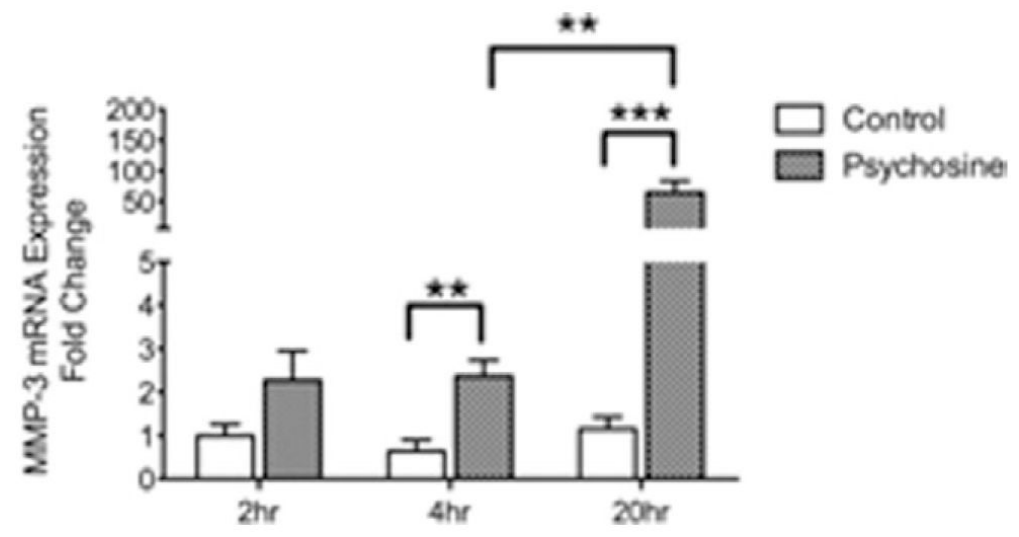

FIGURE 2.

Psychosine transcriptionally regulates MMP-3 expression in primary glial cultures. Primary mixed glial cultures from wild-type mouse were treated with psychosine $(10 \mu \mathrm{M})$ for 2,4 , $24 \mathrm{hr}$ and MMP-3 mRNA expression level was quantified by qRT-PCR. Data represent mean \pm SEM. $N=3$ to $4 /$ treatment/time-point. $* * P<0.01, * * * P<0.001$. 

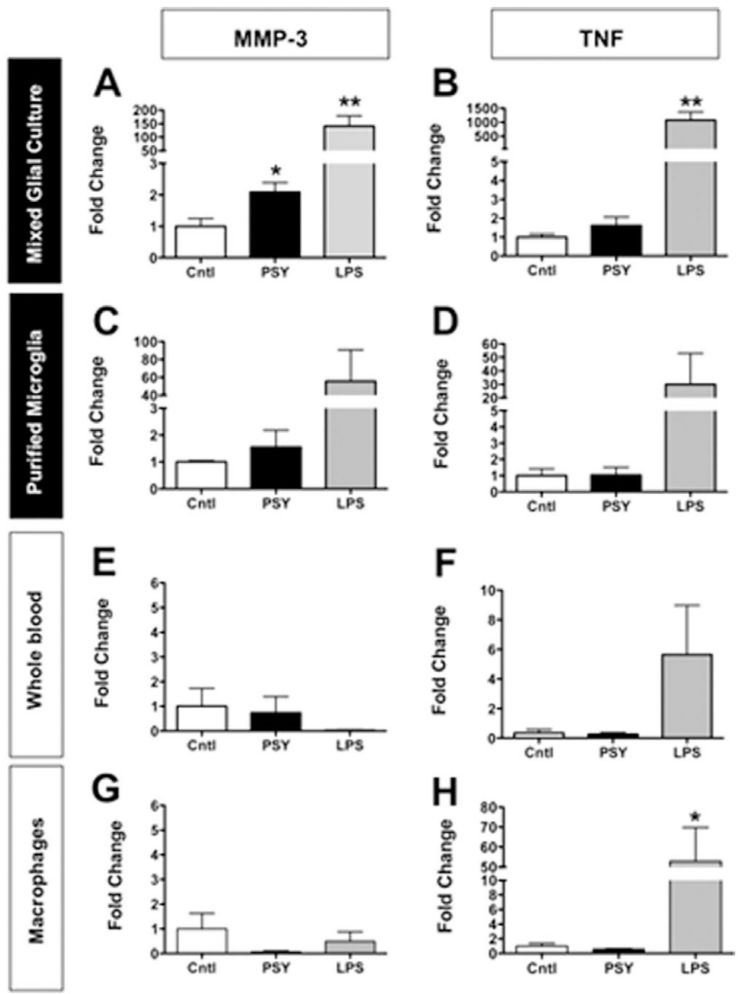

FIGURE 3.

Psychosine regulates MMP-3 expression differently in CNS microglia and peripheral blood cells/macrophages. Mixed glial culture, purified microglia, whole blood white cells, and peritoneal macrophages were treated with psychosine $(10 \mu \mathrm{M})$ or LPS $(10 \mu \mathrm{g} / \mathrm{mL})$ for $4 \mathrm{hr}$, and MMP-3 mRNA expression level was analyzed by qRT-PCR (A, C, E, G). Also, to ensure the cellular responsiveness to stimulus, TNF mRNA expression level was also quantified $(\mathbf{B}, \mathbf{D}, \mathbf{F}, \mathbf{H})$. Note that CNS cells with psychosine treatment had increased MMP-3 expression (A and C), but not peripheral cells (E and G), although peripheral cells had increased TNF expression in response to LPS (F and H). $N=3-4 /$ treatment/cell type. Data represent mean \pm SEM. $* P<0.05, * * P<0.01$. 

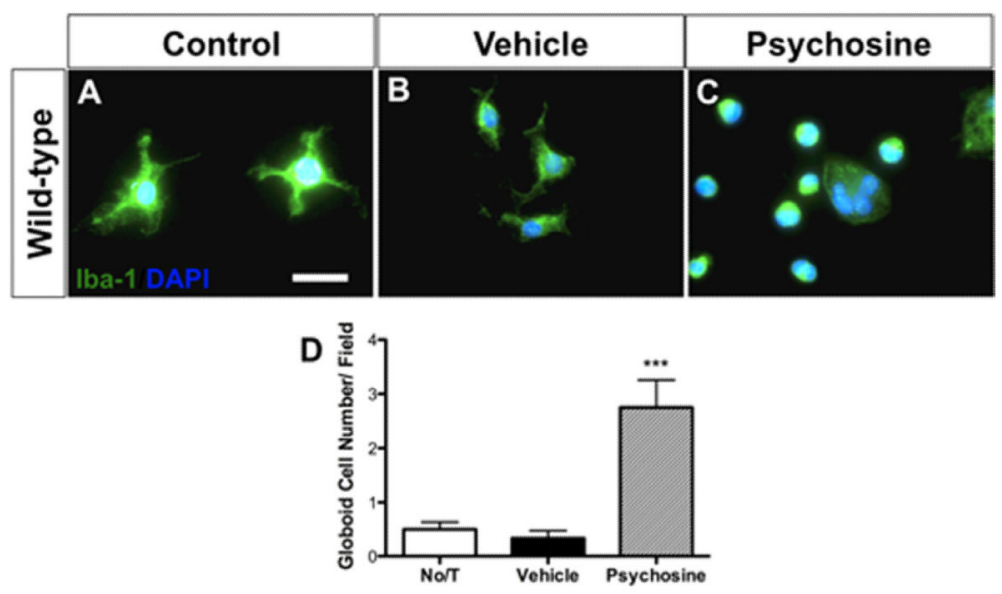

FIGURE 4.

Psychosine induces globoid cell formation in a primary mixed glial culture. (A-D) Addition of pyschosine $(10 \mu \mathrm{M})$ for 7 days significantly increases numbers of Iba-1+ (green) multinucleated globoid cells compared with both controls [no treatment $(\mathrm{No} / \mathrm{T})$ ] and vehicle in a primary mixed glial culture. Data represent mean \pm SEM. $* * * P<0.001$ relative to No/ $\mathrm{T}$. Scale bar $=20 \mu \mathrm{m}$. [Color figure can be viewed in the online issue, which is available at wileyonlinelibrary.com.] 


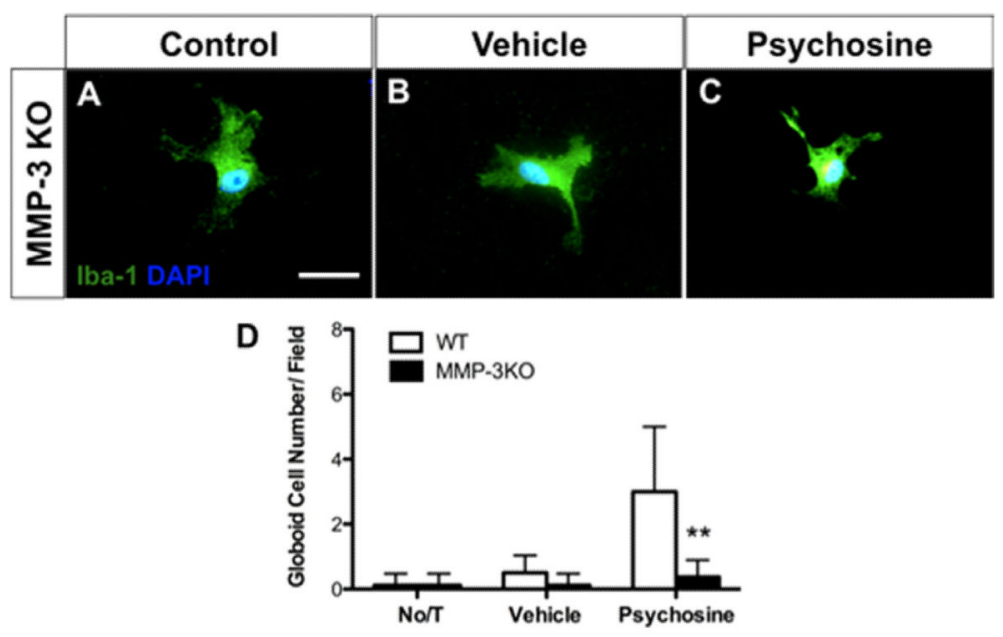

FIGURE 5.

Psychosine-induced "globoid-like cell" formation in vitro requires MMP-3. Primary mixed glial cultures were prepared from MMP-3 KO and WT littermates and then treated with psychosine $(10 \mu \mathrm{M})$ for 7 days. ICC was performed using Iba-1 antibody (green) and DAPI (blue) and the number of multinucleated microglia were quantified. The numbers of Iba-1+ cells did not differ between untreated weight of KO cultures. The prevalence of globoid-like cells observed in weight cultures treated with psychosine was elevated sixfold over vehicle treatment (A-D) but were absent from the MMP-3 KO cultures (D). Data represent $n=8$ / treatment; ${ }^{* *} P<0.01, t$-test versus $\mathrm{WT}$. Scale bar $=20 \mu \mathrm{m}$. [Color figure can be viewed in the online issue, which is available at wileyonlinelibrary.com.] 


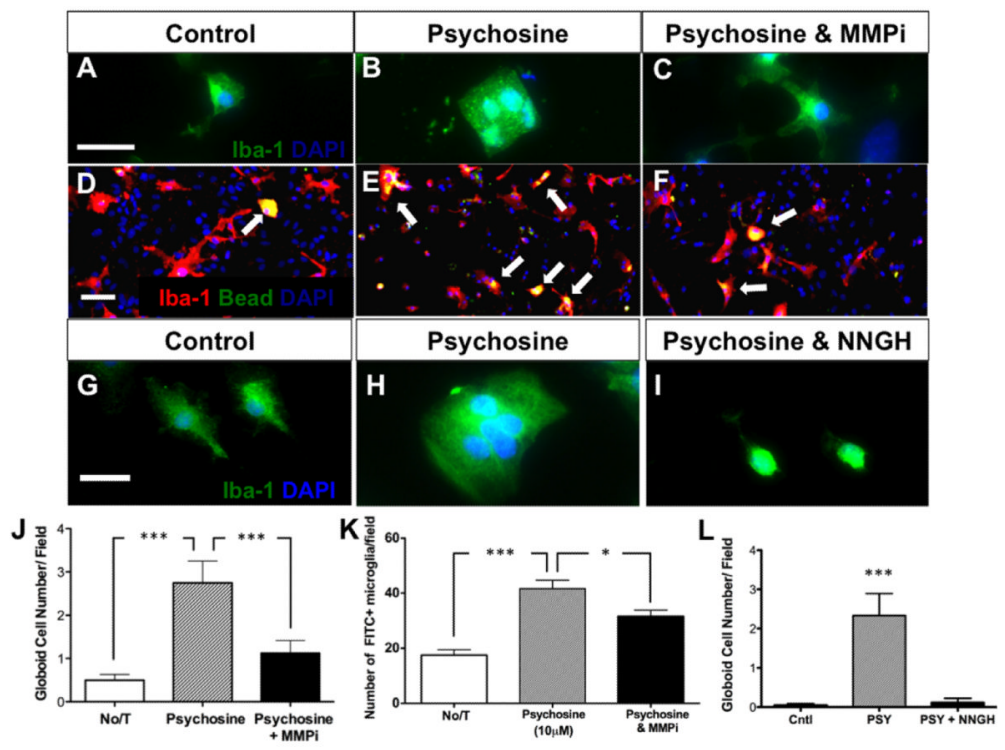

FIGURE 6.

Metalloproteinase inhibition impairs psychosine-induced globoid cell formation and phagocytic activity of microglia. (A-C) Following a 7-day treatment with psychosine (10 $\mu \mathrm{M})$, the presence of Iba-1+ globoid cells (green; nuclei-blue) were significantly increased (A) compared with control (B), while this effect was reversed with the addition of a panMMP inhibitor (MMPi; GM6001, $12.5 \mu \mathrm{M})(\mathrm{C}, \mathrm{J})$. Panel B demonstrates the large amoeboid shape of Iba-1+ cells treated with psychosine, which was reversed with the MMPi. (D-F) Primary mixed glial cultures (Iba-1+ cells-red; FITC+ beads-green; nucleiblue) incubated for last $48 \mathrm{hr}$ of 7 days psychosine treatment with latex FITC-labeled beads (white arrows) demonstrates that psychosine treatment significantly increased the phagocytic activity Iba-1+ cells, which was also significantly decreased by addition of the MMPi (K). Primary mixed glial culture from wild-type mouse $(\mathbf{G})$ was treated with psychosine $(10 \mu \mathrm{M})$ alone $(\mathrm{H})$, or psychosine and NNGH $(0.1 \mu \mathrm{M})$ concomitantly $(\mathbf{I})$ for 7 days. Immunocytochemistry study revealed that psychosine induced Iba-1+ (green) globoid cells containing multiple nuclei (DAPI, blue) $(\mathrm{H})$, but failed to induce globoid cells when NNGH was added together (I). Number of globoid cells was quantified (L). Data represent mean \pm SEM. $* * * P<0.001, * P<0.05$. Scale bar top $=30 \mu \mathrm{m} ;$ middle $=20 \mu \mathrm{m}$; bottom $=$ $18 \mu \mathrm{m}$. [Color figure can be viewed in the online issue, which is available at wileyonlinelibrary.com.] 


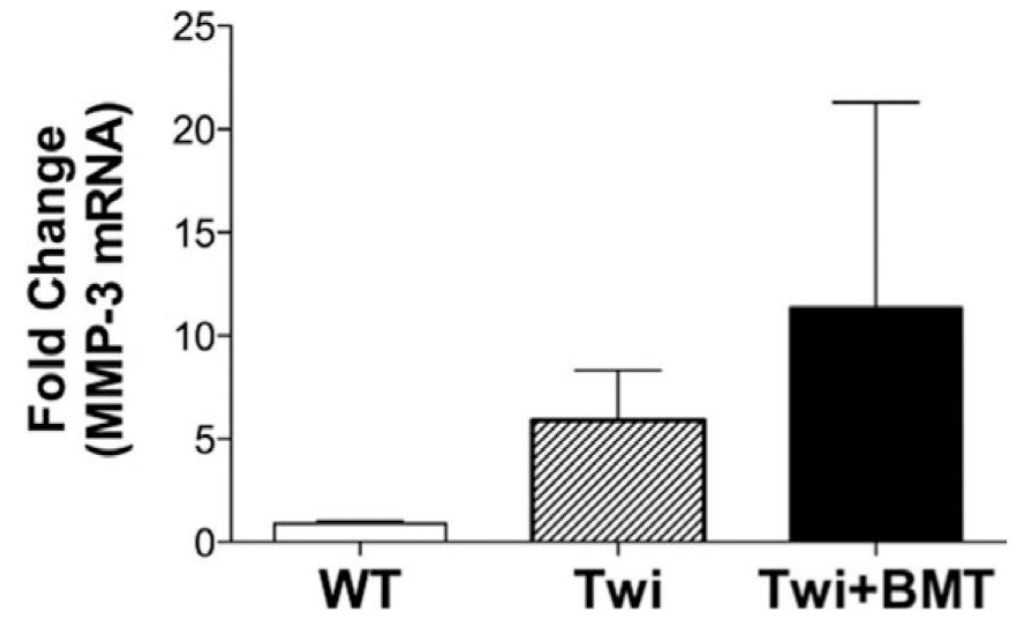

FIGURE 7.

Increased $m m p-3$ mRNA expression in twitcher mouse brain is not attenuated by bone marrow transplantation. qRT-PCR was performed on cDNA derived from mRNA isolated from whole brain homogenates from P40 to $50 \mathrm{WT}$, untreated twitcher, and bone marrow transplanted (BMT)-twitcher mice. Data are presented as fold change of mmp-3 mRNA relative to the expression of GAPDH within each sample ( $N=3-4 /$ time-point/genotype). Data represent mean \pm SEM. 